\title{
Switching valve operated proportional seat valve with momentum flowmeter
}

\author{
YASUKAZU SATO and HIROHISA TANAKA \\ Department of Mechanical Engineering and Materials Science \\ Yokohama National University \\ 156, Tokiwadai, Hodogaya-ku, Yokohama, 240 Japan
}

\section{ABSTRACT}

Mobile or stationary fluid power systems require no leak valves with proportional controllability. Following the developement of a proportionally controlled seat valve with feedback slots, authors have designed an electrohydraulic seat valve with a momentum flowmeter which compensates the flow fluctuation of the valve against load pressure changes. The flow control seat valve operated by a PWM switching valve controls flow rates of $80 \mathrm{~L} / \mathrm{min}$ within $0.1 \mathrm{~s}$. The paper shows transient characteristics of the valve and its simulation results by bond graph analyses.

\section{KEYWORDS}

Fluid Power Systems, Oil Hydraulics, Proportional Seat Valve, PWM Switching Valve, Momentum Flowmeter, Flow Control System

\begin{tabular}{|c|c|}
\hline NOMENCLATURE & $\begin{array}{l}P_{L}: \text { load pressure } \\
P_{S}: \text { supply pressure }\end{array}$ \\
\hline$A:$ cross sectional area of flowmeter & $Q:$ flow rates \\
\hline$A c:$ control chamber area of main valve & $Q c:$ flow rates through feedback slots \\
\hline$A p\left(A p_{m}\right):$ pilot valve opening area $\left(_{m}:\right.$ max. $)$ & $Q_{L}:$ load flow rates \\
\hline As:supply pressure acting area & $Q p:$ pilot flow rates \\
\hline$b$ :damping coefficient of flowmeter spool & $t p:$ PWM width \\
\hline$C_{d}:$ discharge coefficient & $t s:$ PWM carrier \\
\hline$F_{f}:$ flow force & $W c:$ width of feedback slots \\
\hline$k 1, k 2$ :spring constants & $x: 1$ ift of main seat valve \\
\hline$L:$ length between inlet and outlet port & $x_{L}:$ underlap of feedback slots \\
\hline$m:$ mass of flowmeter spool & $y:$ displacement of flowmeter spool \\
\hline$m_{f}$ :mass of workig fluid moving with spool & $\rho:$ fluid density \\
\hline$P c$ : pressure at control & $\tau:$ PWM duty $(=t p / t s)$ \\
\hline
\end{tabular}

Fluid Power. Edited by T. Maeda. (C) 1993 E \& FN Spon. ISBN 0419191003. 
$\kappa$ :area ratio $(=A s / A c)$

$\theta:$ discharge angle of jet

\section{INTRODUCT ION}

Fluid power systems of construction machinery or extrusion machinery require no leak electrohydraulic control valves which have capabilities of continuous and wide range flow control and quick response control under high pressure. Following the developement of a proportionally controlled seat valve(1), (2), (3) with position feedback slots, authors have designed an electrohydraulic seat valve operated by a PWM switching pilot valve (4). The seat valve controls flow rates of $801 / \mathrm{min}$ within $10 \mathrm{~ms}$ in no-load condition by open roop control. The present paper discribes a flow control system with proportional controllability insensitive to load pressure disturbances. The system is named the flow sensing seat valve which consists of a combination of the seat valve and a momentum flowmeter ${ }^{(5)}$. The paper shows the fundamental characteristics of the flow sensing seat valve and the analytical results of dynamics of the system.

\section{PROPORTIONAL SEAT VALVE OPERATED BY SWITCHING VALVE}

Figure 1 shows the configuration of the proportional seat valve. The valve consists of a main seat valve with feedback slots and a plot valve. The lift of the main valve is expressed by the following equation.

$$
x=\frac{A p}{W C} \sqrt{\frac{\kappa}{1-\kappa}}-x_{L}
$$

where $A p$ is valve opening area of the pilot valve, $W_{c}$ is width of the slot, $\hat{t}$ is area ratio, and $x_{L}$ is underlap of the slot. Authors apply a switching valve to control the pilot opening area $A p$. The main valve opens proportionally to the pilot valve

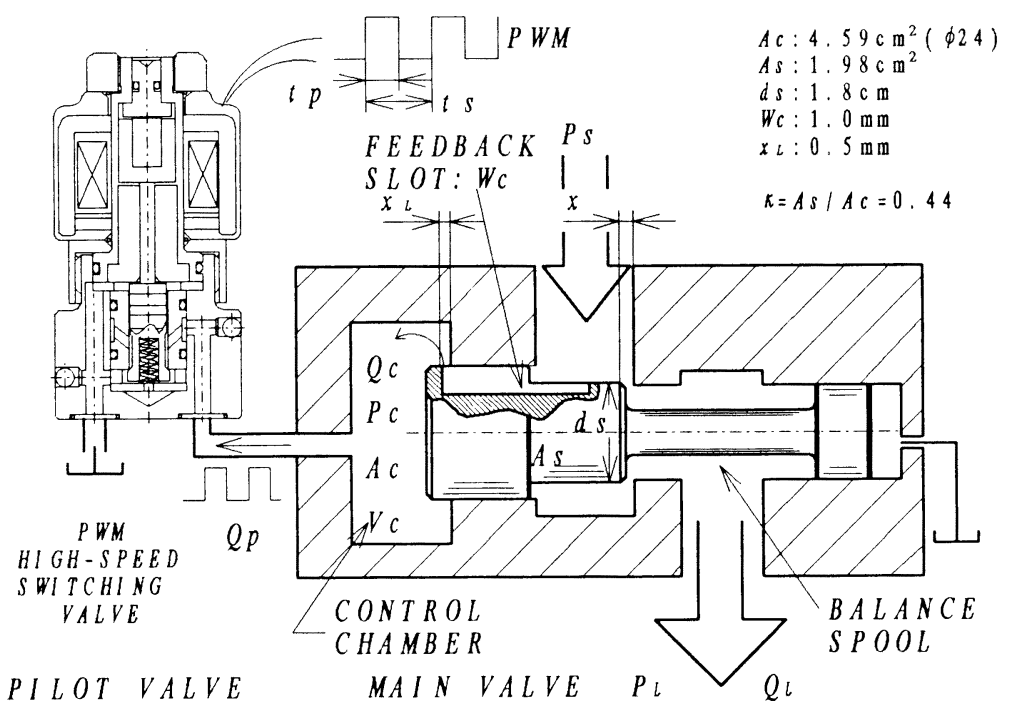

Fig. 1 Proportional seat valve controlled by a PWM switching valve 
operation which is controlled by PWM signals (B). At constant pressure difference, the pilot valve flow rate $Q p$ is proportional to the duty of pulse width $(=t p / t s)$. The equivalent opening area of the pilot valve is expressed by

$$
A p=\tau A p_{m}=\frac{t p}{t s} A p_{m}
$$

The maximum pilot flow rates are $4 \mathrm{~L} / \mathrm{min}$ at pressure difference of $5 \mathrm{MPa}$ on the PWM currying frequency of $80 \mathrm{~Hz}$. The main valve magnifies flow rates fifty times as large as the pilot valve and controls flow rates of $80 \mathrm{~L} / \mathrm{min}$ within $10 \mathrm{~ms}$.

\section{MOMENTUM FLOWMETER AND BASIC CHARACTERISTICS}

\section{Principle of flow measurement}

The momentum flowmeter is illustrated in Fig. 2. The principle of flow measurement is measuring the flow force acting on the spool (7). The momentum force balances with the spring force. In Fig. 2, the fluid flow from A port to the chamber through the $45^{\circ}$ slanted ports makes jet flow with momentum.
The flowmeter is able to measure flow rates of both side flows.

\section{Characteristics of the flowmeter}

The flow force working on the spool is expressed by

$$
F_{f}=\rho \frac{Q|Q|}{C_{d} A} \cos \theta+\rho L \dot{Q}-m_{f} \ddot{y}
$$

where the direction of flow from $A$ to $B$ is defined to be positive. The dynamics of the spool is expressd by

$$
m \ddot{y}+b \dot{y}+(k 1+k 2) y=F_{f} .
$$

From Eq. (4), the steady state displacement is balanced

$$
y=\rho \frac{Q|Q|}{C_{d} A(k 1+k 2)} \cos \theta .
$$

The natural angular frequency of the flowmeter is designed $\omega_{n}(=\sqrt{(k 1+k 2) / m})$ $=440 \mathrm{rad} / \mathrm{s}(\sim 70 \mathrm{~Hz})$. The steady state characteristics is shown in Fig. 3. The steady state characteristics agrees with the

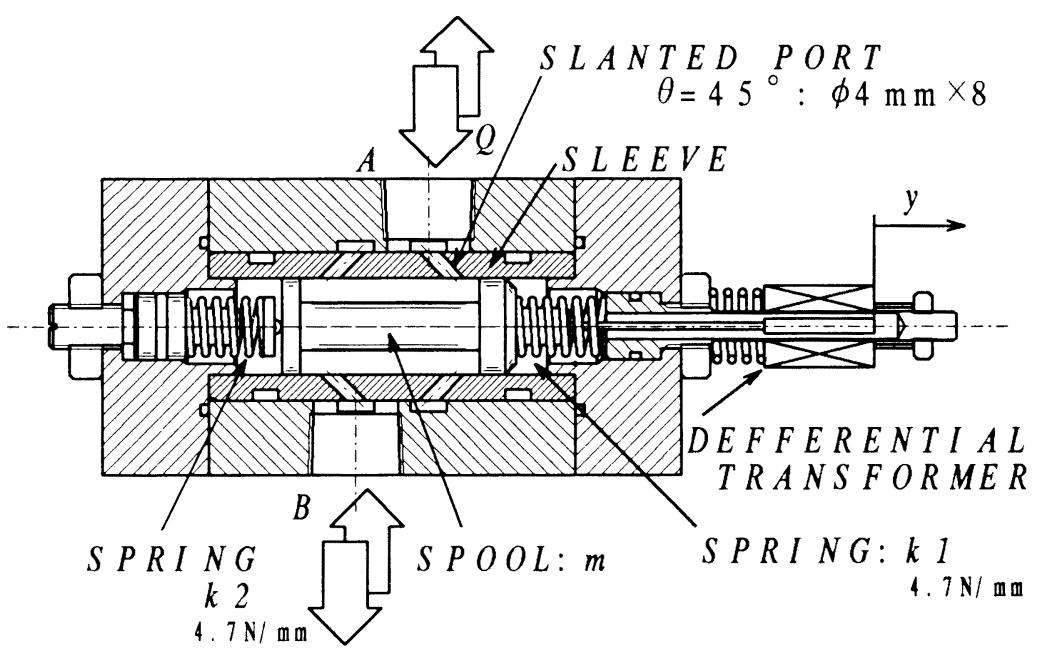

Fig. 2 Momentum flowmeter 
theoretical relations. The spool works within 2 \% hysterisis, however, the resolution in the low flow rates range (below $10 \mathrm{~L} / \mathrm{min}$ ) is not good because of square curve characteristics. Figure 4 shows the transient characteristics of the flowmeter which are compared with pressure changes of the small fluid resistance orifice serially connected to the flowmeter. The flowmeter responds in $35 \mathrm{~ms}$ delay compared to the pressure changes of the flow step from 30 to $60 \mathrm{~L} / \mathrm{min}$. The dynamic response for alternative flow change is shown in Fig. 5. The rectangulaly flow

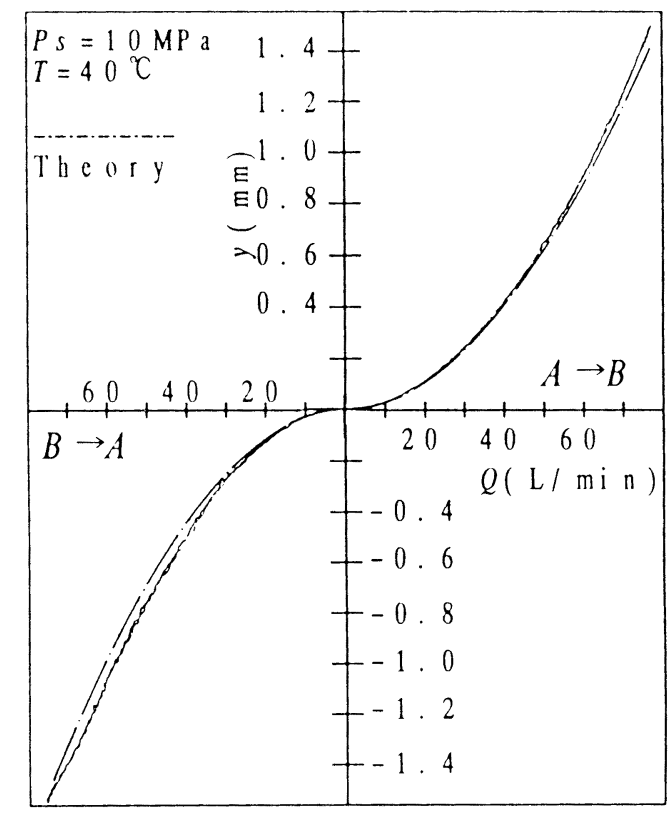

Fig. 3 Steady state characteristics of the momentum flowmeter

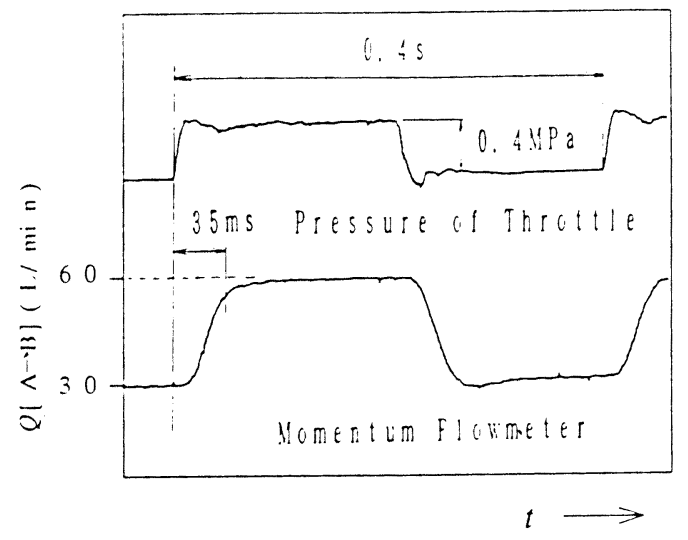

Fig. 4 Transient characteristics of stepped flow rates change changes are given by a four ports valve with $10 \mathrm{~ms}$ delay. The flowmeter measures the flow changes of amplitude of $\pm 35 \mathrm{~L} / \mathrm{min}$ without the transient instability. Figure 6 shows the pressure loss characteristics of the flowmeter for which working fluid is VG32 at $40^{\circ} \mathrm{C}$.

\section{PROPORTIONAL SEAT VALVE WITH MOMENTUM FLOWMETER}

\section{Characteristics of the flow sensing} seat valve

The experimental circuit for the flow sensing seat valve with the momentum flowmeter is shown in Fig. 7. The controller calculates the pulse width of PWM rates for the pilot valve. The signal is given by the error between the reference flow rates $Q r$

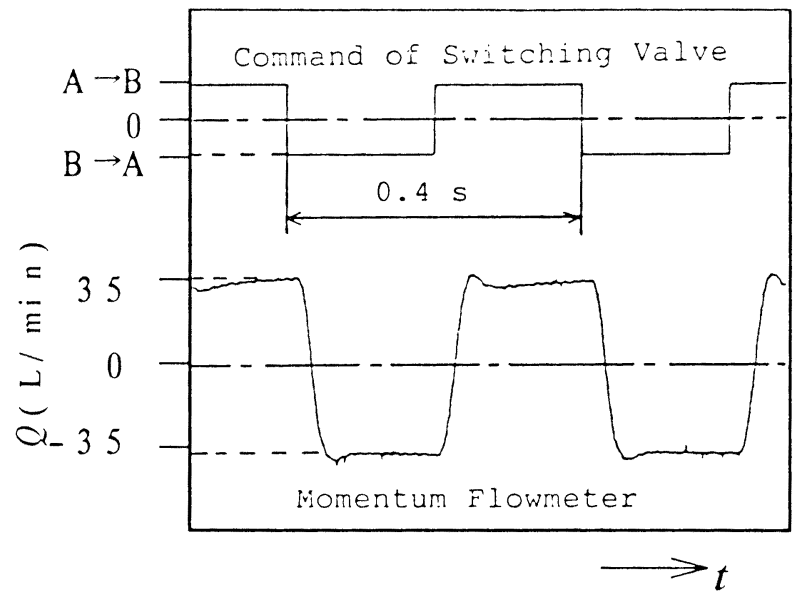

Fig. 5 Transient characteristics of alternating flow rates change

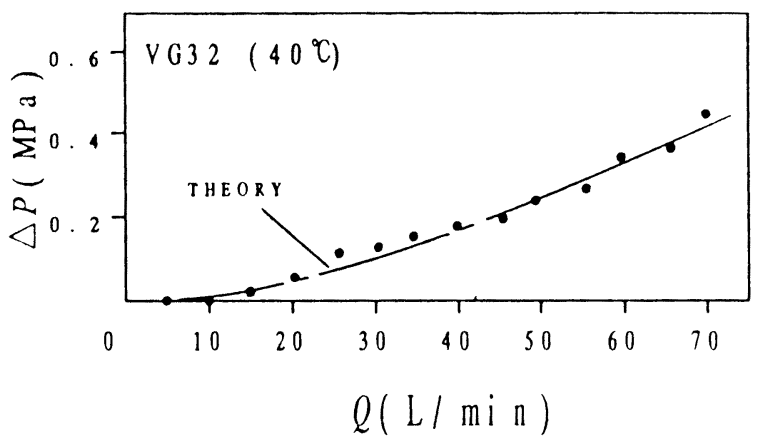

Fig. 6 Pressure loss of the momentum flowmeter 
FLOW SENSING SEAT VALVE

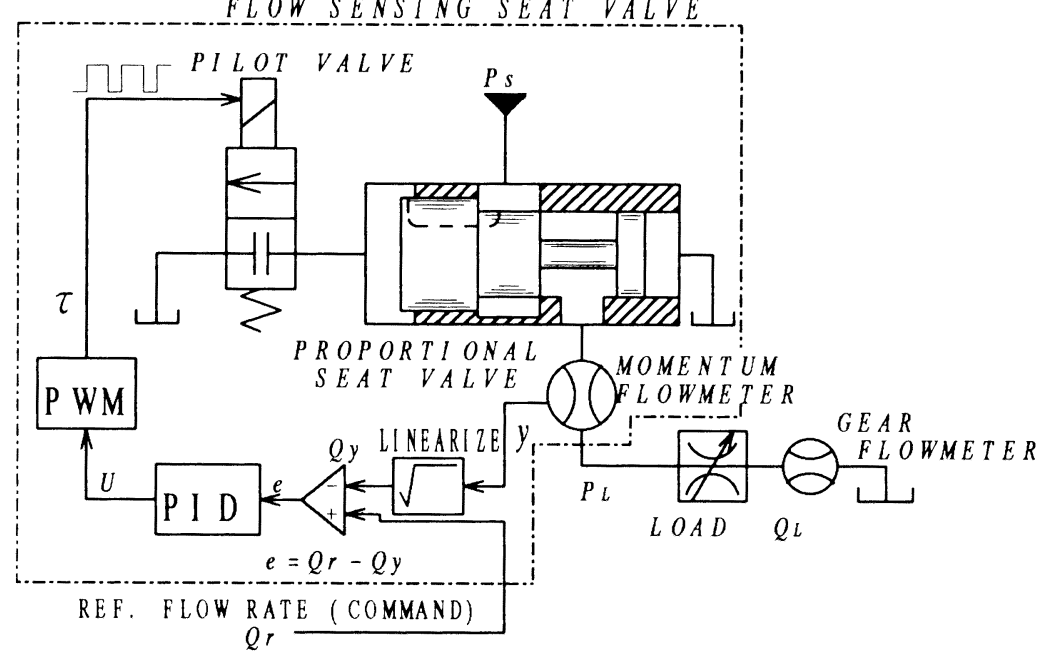

Fig. 7 Flow control system

(Flow sensing seat valve with load)

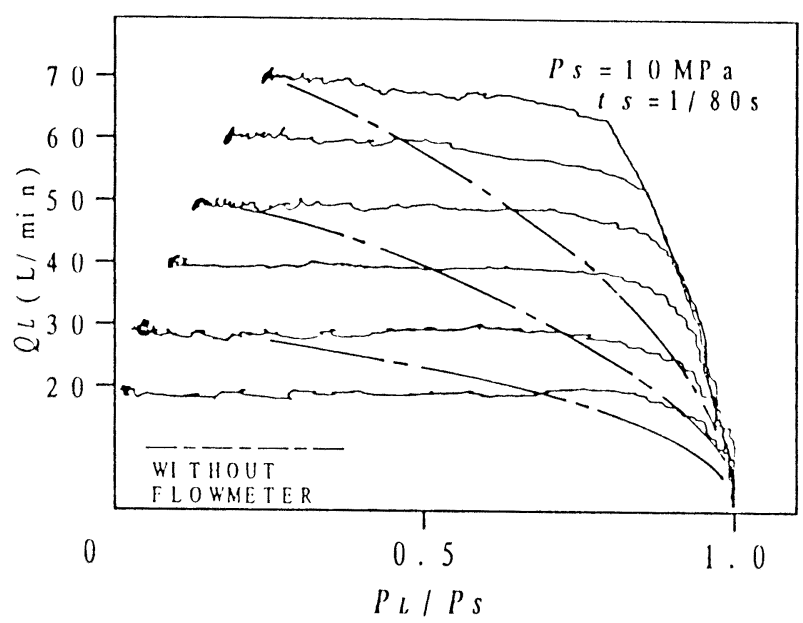

Fig. $8 P_{L}-Q_{L}$ characteristics

and the measured flow rates $Q y$. In the testing circuit, an variable orifice and the gear flowmeter (KRACHT VLUTRONIC VC1, $1.05 \mathrm{cc}$ /pulse) are connected serially for loading the valve and calibrating the flow rates. Figure 8 shows the characteristics of controlled flow rates versus load pressure. The compensation by the flowmeter makes it possible to control the flow rates insensitively against the load pressure change. Figure 9 shows the transient characteristics of the valve without load. The valve controls the stepped flow rate change from 30 to $60 \mathrm{~L} / \mathrm{min}$ within $80 \mathrm{~ms}$. From Fig. 10, we

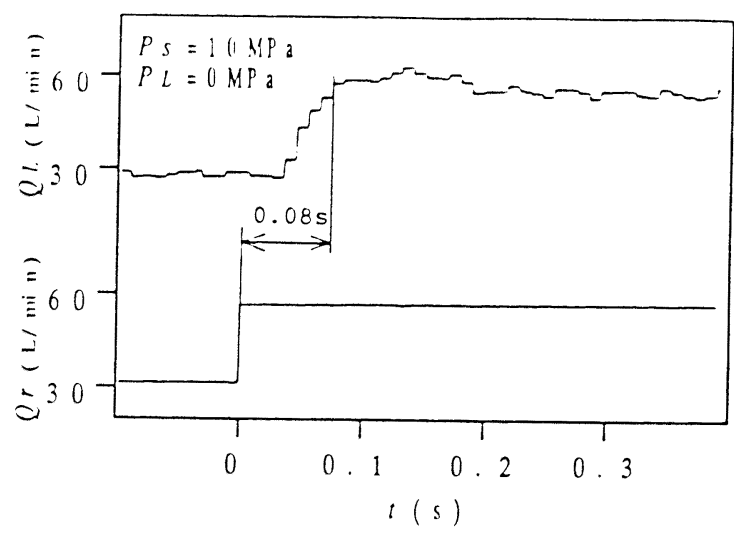

Fig. 9 Step response (without load)

( $Q_{r}$ :Command, $Q_{L}$ :Gear flowmeter)

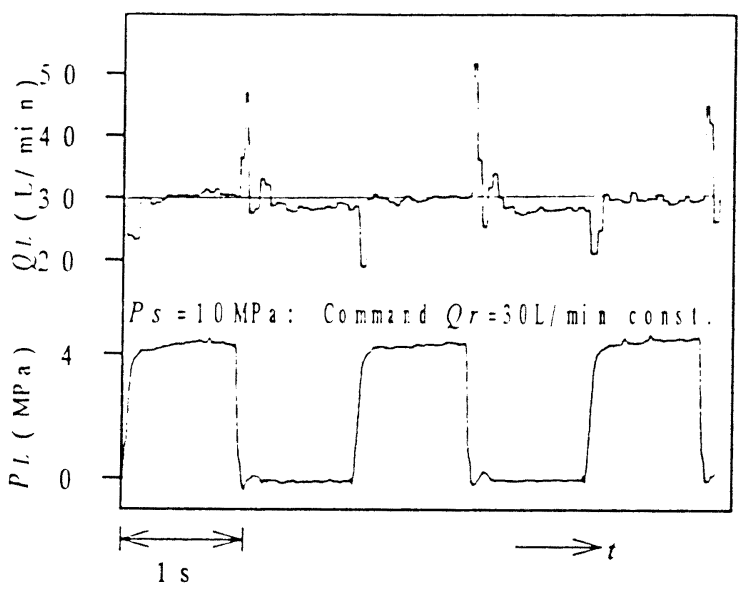

Fig. 10 Flow control dynamics against load pressure changes 
can see the insensitivity of the valve against load pressure disturbance. The valve controlls flow rates within 0.1 s against the stepped load pressure change from 0 to $4 \mathrm{MPa}$.

\section{Bond graphs}

The dynamics of the valve have been simulated analytically by bond graphs. The mathematical model of the flow sensing seat valve is expressed by bond graphs in Fig. 11. Figure 12 shows one of simulated results using a ready-published soft ware BGSP(8). The BGSP simulates a little flow rates change at the pressure change due to the control lag.

\section{CONCLUSION}

The proportional seat valve with the momentum flowmeter has been developed. The high-speed switching pilot valve controlled by PWM signals is applied to the operation of the main seat valve. The valve controls the stepped flow rate from 30 to $60 \mathrm{~L} / \mathrm{min}$ within $0.08 \mathrm{~s}$, and compensates load pressure change of 4 MPa within $0.1 \mathrm{~s}$. The simulations by bond graphs agree with the measured results of the transient flow rates change due to the control lag.

\section{AKNOWNLEDGEMENT}

Authors would like to thank Mr. Yusaku Nozawa of Hitachi Construction Machinery Co., Ltd. for making the seat valve, and Mr. Kenji Masuda of Daikin Industry for developing the flowmeter.

\section{REFERENCES}

1) Andersson, Bo R., On the Valvistor, A Proportionally Controlled Seat Valve. Linköpin, T. H. , Dr. Dissertation, No. 108(1984), 36. 2) Luomaranta.M.K., Valvistor Based Modern Servo Package, Proc. JHPS Inter. Fluid Power Symp, Tokyo, 1989, 557.

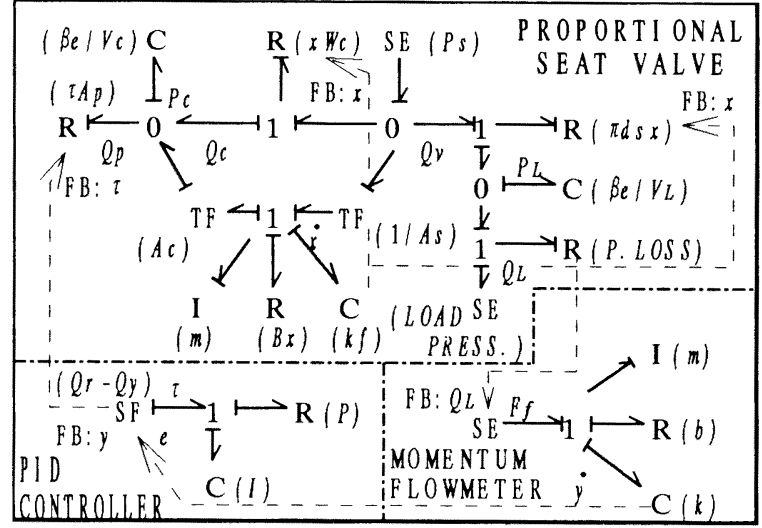

Fig. 11 Bond graphs for the flow sensing seat valve with load

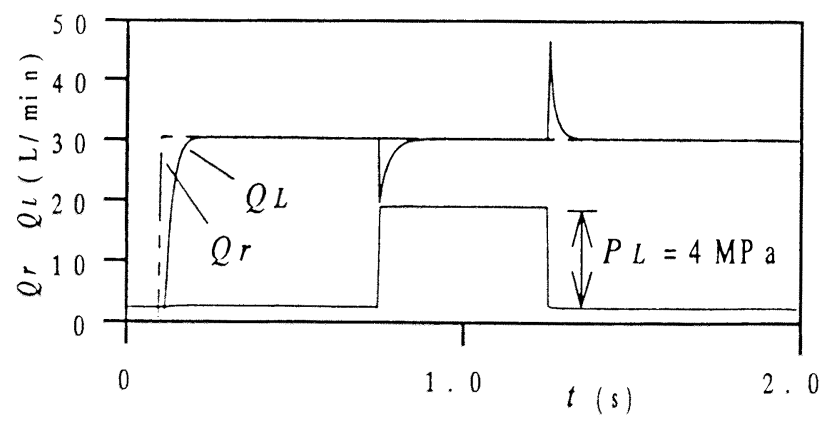

Fig. 12 Simulated results to load pressure changes

3) Andersson, Bo R., Rego Concept Proportinal Load and Pressure Compensated Cartridge Valve for Mobile Applications, SAE-paper 841112, (1984).

4) Sato, Y and Tanaka, H, Proportional Seat Valve Controlled by High-Speed Switching valve, Trans. of JSME Vol.57B. No.533, (1991), 178-181 (in Jpn.)

5) Sato, Y and Tanaka, H, Developement of the Momentum Flowmeter, Pre prints of JHPS 1991 autumn, 1-4. (in Jpn.).

6) Tanaka, H, Pulse Flow Control Valves and Simplified Proportional Valves, Proc. 8 th Inter. Fluid Power Symp., BHRA, Birmingham, U. K., April 1988, 351-368.

7)Merritt,H. E., HYDRAUL IC CONTROL SYSTEMS, John Wiley \& Sons, 1967, 101-105.

8) JHPS, Reports according to an improvement of the BGSP, Sub Text (1992), 20(in Jpn.) 